\section{Human eyelid conditioning with paraorbital shock as the US*}

\author{
I. GORMEZANO, University of Iowa, Iowa City, Iowa 52240 \\ and \\ C. D. FERNALD, Hollins College, Hollins College, Va. 24020
}

The purpose of the present investigations was to delineate associative and nonassociative effects of paraorbital shock on conditioning (Experiment 1); and to determine the effects of shock intensity on the frequency and form of eyelid CRs (Experiment 2). The studies revealed: (1) unequivocal evidence of conditioning with paraorbital shock; (2) that rate and asymptotic level of conditioning was a direct function of shock intensity; and (3) a large proportion of Ss could be classified as presumed "voluntary responders." The relevance of these findings to the law of effect and "voluntary responder" controversy in human eyelid conditioning were discussed.

Investigators in human eyelid conditioning have only occasionally employed paraorbital shock as the US (e.g., Cason, 1922; Bernstein, 1934; Logan, 1951). That paraorbital shock has not been more extensively employed suggests a general failure to recognize the potential clarification its use might afford, relative to a corneal air puff US, to the issues of the operation of the law of effect (Solomon \& Brush, 1956, p. 250) and presumed presence of "voluntary responders" (Spence \& Ross, 1959) in human eyelid conditioning. Furthermore, in those few instances in which paraorbital shock has been employed, no systematic assessment has been made of its effects on nonassociative contributors to human eyelid conditioning performance. Accordingly, the purpose of the present investigations was to delineate associate and nonassociative effects of paraorbital shock on conditioning performance (Experiment 1) and to determine the effects of shock US intensity on the frequency and form of eyelid CRs (Experiment 2).

\section{EXPERIMENT 1}

Apparatus

The apparatus and recording technique has been described in detail elsewhere (Gormezano, 1966; Moore \& Gormezano, 1961). The CS was a 70-dB (re .0002 dynes $/ \mathrm{cm}^{2}$ ) 1,000-Hz tone of $500-\mathrm{msec}$ duration. The US was a 1.2-mA 1-msec dc shock delivered to the paraorbital region of S's right eye by 9-mm-diam silver electrodes embedded in Plexiglas cups filled with Beckman Electrolyte Gel. Beckman adhesive collars were employed to fasten one (inactive)

*This research was supported by Grant GB-7907X from the National Science Foundation. Requests for reprints should be addressed to I. Gormezano, Department of Psychology, University of Iowa, Iowa City, Iowa 52240. electrode $2 \mathrm{~cm}$ dorsal to the external canthus of S's right eye and the other (active) electrode $2 \mathrm{~cm}$ below the external canthus.

Subjects and Procedure

one hundred males from introductory psychology courses, paid $\$ 2.00$ for their participation, were assigned randomly to five groups of 20 Ss each. Four of the groups were nonassociative controls: Group N received neither the CS nor the US; Group CS-A received 60 CS-alone trials; Group US-A received 60 US-alone trials; and Group $R$ received $60 \mathrm{CS}$-alone trials and 60 US-alone trials, randomized within blocks of 20 trials. The fifth group, Group CS-US, was the classical conditioning group, and it received 60 paired presentations of the CS and US at a CS-US interval of $500 \mathrm{msec}$. All groups, except Group $R$, received their trials at random intertrial intervals of 25,30 , and $35 \mathrm{sec}$ (mean of $30 \mathrm{sec}$ ), whereas
Group $R$ received its trials at random intertrial intervals of 10,15 , and $20 \mathrm{sec}$ (mean of $15 \mathrm{sec}$ ). The latencies of the first eyelid closures of at least $1 \mathrm{~mm}$ in amplitude in the intervals from 0 to $150 \mathrm{msec}$ (alpha responses) and 151 to $500 \mathrm{msec}$ (CRs) after CS onset were recorded. For Groups $N$ and US-A, the observation interval was the same 500-msec interval normally occupied by the CS in Group CS-US. Results and Discussion

The distribution of response latencies, presented in the left-hand panel of Fig. 1, reveals that groups receiving the CS (Groups CS-US, R, and CS-A) showed a distribution of short-latency responses commonly taken as reflex (alpha) responses to the CS (Grant, 1943). As is usually observed in human eyelid conditioning experiments employing a corneal air puff as the US, these alpha responses were distributed about a 75-msec mode with a latency range of approximately $50-125 \mathrm{msec}$. The distributions also reveal that while Group CS-US showed a high frequency of responses in the 150 - to 500 -msec interval, the responses of all control groups were few in number and unsystematic in their temporal distribution.

The right-hand panel of Fig. 1 presents experimental and control group mean percentage $C R$ acquisition curves in blocks of five trials. Inspection of the figure reveals that Group CS-US showed relatively rapid acquisition of CRs and reached a terminal level of responding of about $70 \%$. In contrast, the control groups showed undifferentiated low levels of responding and no systematic changes in response frequency over trial blocks. As would be expected, an analysis of variance on percentage CRs
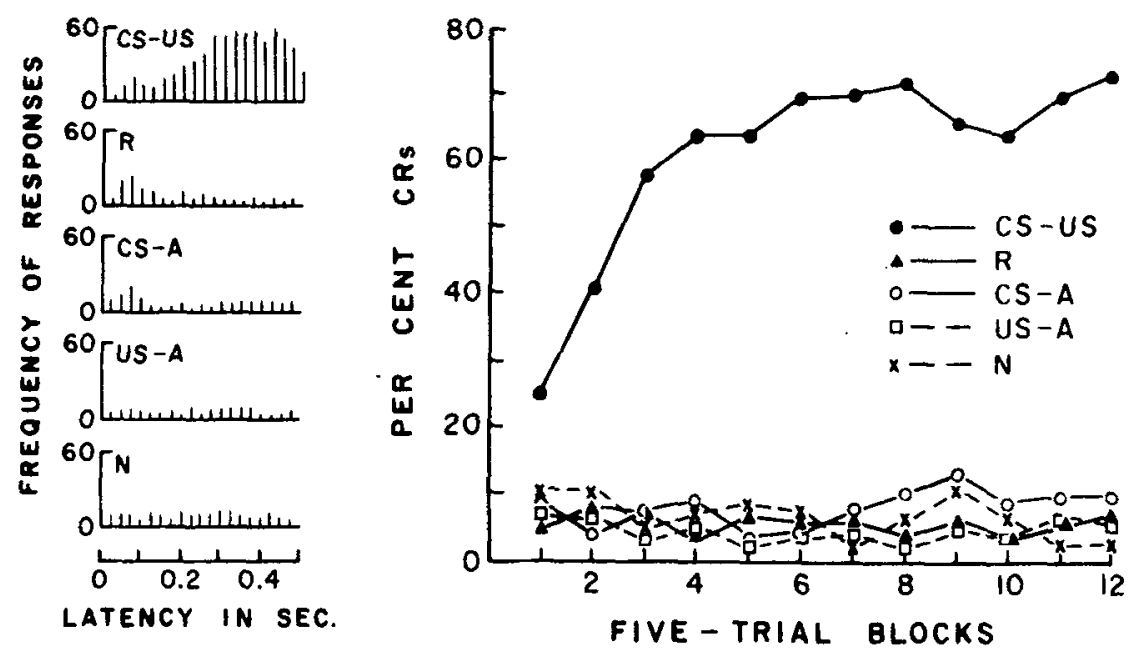

Fig. 1. The distribution of response latencies (left-hand panel) and mean percentage CR acquisition curves in blocks of five trials (right-hand panel) for experimental and control groups. 
revealed significant groups, blocks, and Groups by Blocks effects (all ps $<.001)$. Application of the Duncan range test to the significant group's mean source of variation indicated that all control groups were significantly different from Group CS-US (all ps $<.001$ ) but not from one another. Consequently, the present data provide unequivocal evidence that, with a paraorbital shock US, the conditioning performance of Group CS-US cannot be attributed to sensitization or pseudoconditioning or to US-produced changes in base rate frequency of eye blinks.

\section{EXPERIMENT 2}

Apparatus

A differentiator was added to the equipment employed in Experiment 1 to provide an oscillograph record of the first time derivative of eyelid movement from one of the two recording systems.

Subjects and Procedure

One hundred and eight male Ss from introductory psychology courses, paid $\$ 2.00$ for their participation, were assigned randomly to three experimental groups (Groups .8P, 1.7P, and 2.6P) of $24 \mathrm{Ss}$ each and to three control groups (Groups .8R, 1.7R, and 2.6R) of 12 Ss each. Groups $.8 \mathrm{P}, \quad 1.7 \mathrm{P}$, and $2.6 \mathrm{P}$ received 10 CS-alone trials (one given every 10th trial) and 90 CS-US trials at US shock intensities of $.8,1.7$, and $2.6 \mathrm{~mA}$, respectively, whereas Groups .8R, $1.7 \mathrm{R}$, and $2.6 \mathrm{R}$, given US shock intensities corresponding to their respective experimental groups, received 100 CS-alone and 90 US-alone trials, randomized within blocks of 10 trials with the restriction that every 10th trial be a CS-alone trial. For half of the $S s$ in each experimental group, the first time derivative of all CRs and of URs on the first five trials (or available fraction thereof) were recorded. All other procedures and parameters of the experiment were the same as those employed in Experiment 1. Results

Figure 2 presents experimental and control group mean percentage CR acquisition curves in blocks of 10 trials. Examination of performance of the experimental groups reveals orderly acquisition curves, with rate of $\mathrm{CR}$ acquisition and asymptotic level of responding being an increasing function of US intensity. Analysis of variance corroborated these descriptive characteristics of experimental group performance by revealing significant effects of US intensity $(F=10.76$, $\mathrm{d} f=2 / 69, \quad p<.001)$, blocks $(\mathrm{F}=21.45, \mathrm{df}=9 / 621, \mathrm{p}<.001)$, and US Intensity by Blocks ( $F=1.91$, $\mathrm{df}=18 / 621, \mathrm{p}<.05)$. In contrast, examination of the performance of the

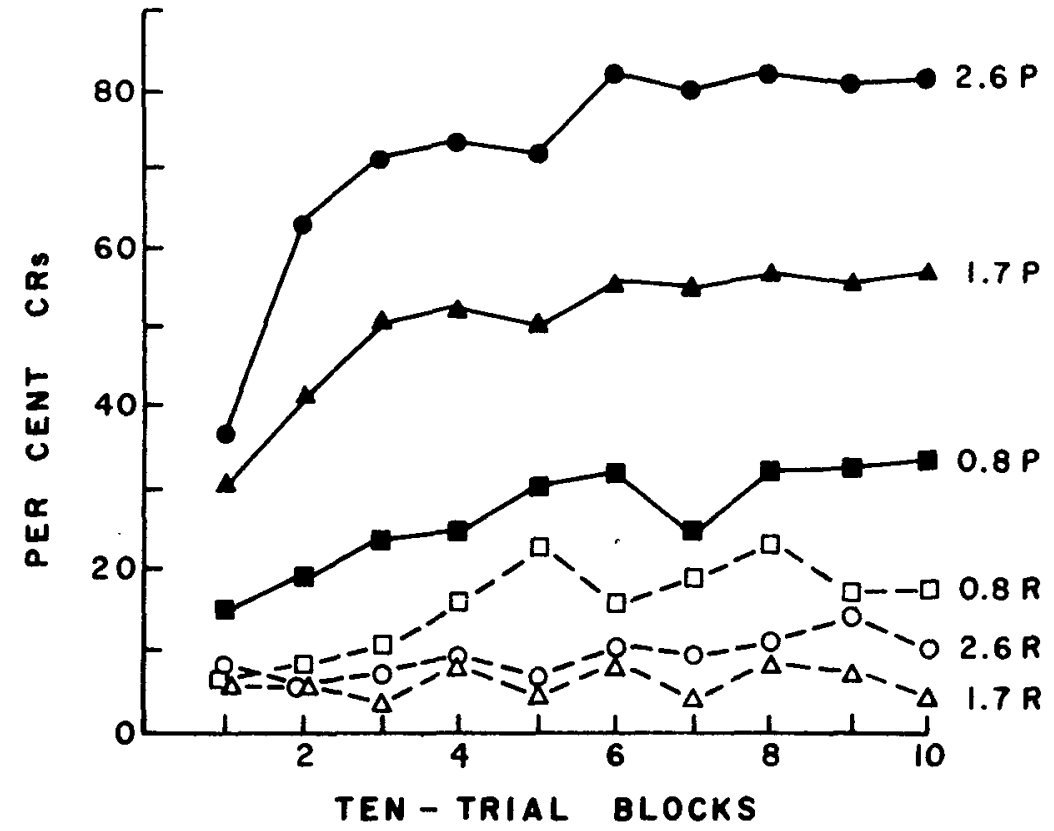

Fig. 2. The mean percentage acquisition CR curves plotted in blocks of 10 trials for experimental and control groups, with US intensity as the parameter.

control groups reveals that, except for Group .8R, overall level of responding was approximately $10 \%$ and that over trial blocks no orderly changes in response frequency occurred. The relatively high level of responding of Group .8R can be accounted for mainly by the extremely high blink rate of a single $S$ (82\% responding during Trial Blocks 4-10). An analysis of variance of control group performance revealed no significant effects of US intensity, blocks, or US Intensity by Blocks. Multiple comparisons between percentage CRs of the experimental and respective control groups by Winer's (1962) method of unweighted means for unequal sample sizes revealed that, except for the paired-unpaired and Paired-Unpaired by Blocks effect of the 8-mA contrast, all paired-unpaired, blocks, and Paired-Unpaired by Blocks effects of the three comparisons were significant (all ps $<.005$ ).

The CRs of half the experimental Ss in each group (i.e., those Ss for which the first derivative of CRs and URs had been recorded), were analyzed according to the slope-of-closure criterion suggested by Hartman \& Ross (1961) for classifying Ss as "voluntary responders" when no ready signal is employed. Accordingly, Ss who gave $50 \%$ or more of their CRs with first time derivatives greater than $35 \%$ of the mean derivative of their first five URs were classified as "voluntary responders." The percentage of Ss classified as "voluntary responders" in Groups .8P, 1.7P, and $2.6 \mathrm{P}$ were $83 \%$,
$70 \%$, and $83 \%$, respectively. DISCUSSION

The finding of no significant differences in frequency of responding among the control groups indicates that the ordered effects of US intensity on rate and asymptotic level of performance of the experimental groups was a function of the CS-US pairing operation. Furthermore, the positive relationship between US intensity and $\mathbf{C R}$ frequency is consistent with the findings of studies manipulating the intensity of a corneal air puff (e.g., Gormezano \& Moore, 1962; Prokasy, Grant, \& Myers, 1958).

One persistent theoretical account of the mechanism of reinforcement in classical conditioning (e.g., Perkins, 1968; Schlosberg, 1937) is the contention that the law of effect account of instrumental conditioning is applicable to classical conditioning. In its most general form, the law of effect account holds that CR-US overlap modifies the sensory consequences of the US to provide the source of reinforcement of CRs. Because the reinforcement mechanism can become operative only after an anticipatory $C R$ has been made, the formulation appeals to adventitious responding, a factor extrinsic to the theory, to account for initial CR occurrence. This logical deficiency in accounting for initial CR occurrence could be removed by a law of effect account which assumes that the UR o perates to modify the sensory consequences of the US to provide the source of reinforcement for initial CR occurrence. For the present 
experiments, however, the $1-\mathrm{msec}$ duration of the US and 25- to 40-msec minimum latency of the UR preclude the overlap of the US and UR and, hence, the possibility that the UR modified the sensory consequences of the US. Furthermore, the use of paraorbital shock in the present studies makes both the US-UR and CR-US overlap interpretation of reinforcement a less than compelling argument.

The assertion that CRs are reinforced through its operating to modify the effects of the US is also related to the "voluntary responder" controversy in human eyelid conditioning (Gormezano, 1965; Spence \& Ross, 1959). Spence and his associates have argued for the elimination of Ss who give a high incidence of CRs of "voluntary form" (i.e., short latency, sharp closure, and long duration). Supposedly, these Ss blink either to comply with the presumed intent of the $E$ or to reduce the noxiousness of the air puff US. Assuming, as suggested above, that CRs overlapping paraorbital shock are not likely to modify the US, the present investigations should have provided a direct experimental method for effectively eliminating from consideration those "voluntary responders" who are presumed to blink to reduce the noxiousness of the US. Yet, the proportion of $\mathrm{Ss}_{8}$ in Experiment 2 classified as "voluntary responders" was considerably larger than the $12 \%-60 \%$ of Ss so classified by the derivative criterion in studies employing the corneal air puff (e.g., Hartman \& Grant, 1962; Hickok, Grant, North, 1965; Levy, Grant, \& Clark, 1964). While it could be argued that the discrepancy arose from inappropriate application of the derivative criterion to a shock US, examination of the topographical features of the CRs revealed many responses of "voluntary form" (i.e., short latency, sharp closure, and long duration). In addition, the topography of URs did not appear to differ from those we have observed in studies involving the manipulation of the intensity of a corneal air puff.

It is possible, of course, that anticipatory blinks do modify the sensory consequences of paraorbital shock. However, if this were the case, and one accepts the rationale for "voluntary responders" provided by Spence \& Ross (1959), one would expect a greater proportion of Ss to be classified as "voluntary responders" as US intensity increased. There was, however, no systematic change in the proportion of "voluntary responders" with variation in US intensity. It also seems unreasonable to suggest that the lowest shock value was so intense that the upper limit for proportion of "voluntary responders" had been reached, since by Trial Block 10 , the frequency of URs of this group was only $69 \%$. Thus, in addition to the methodological limitations involved in classifying Ss as "voluntary responders" (see Gormezano, 1965, pp. 63.67), the findings of Experiment 2 question its construct validity.

\section{REFERENCES}

CASON, H. The conditioned eyelid reaction. Journal of Experimental Psychology, 1922, 5, 153-195.

BERNSTEIN, A. L. Temporal factors in the formation of conditioned eyelid reactions in human subjects. Journal of General Psychology, 1934, 10, 173-197.

GORMEZANO, I. Yoked comparisons of classical and instrumental conditioning of the eyelid response; and an addendum on "voluntary responders." In W. F. Prokasy (Ed.), Classical conditioning: A s y p o s i u m. Ne w Y o r k Appleton-Century-Crofts, 1965.

GORMEZANO, I. Classical conditioning. In J. B. Sidowski (Ed.), Experimental methods and instrumentation in prychology. New York: McGraw-Hill 1966.
GORMEZANO, I., \& MOORE, J. W. Effects of instructional set and UCS intensity on the latency, percentage, and form of the eyelid response. Journal of Experimental Psychology, 1962, 63, 487-494.

GRANT, D. A. Sensitization and association in eyelid conditioning. Joumal of Experimental Psychology, 1943, 32, 201-212.

HARTMAN, T. F., \& GRANT, D. A. Effects of pattern of reinforcement and verbal information on acquisition, extinction, and spontaneous recovery of the eyelid CR. Journal of Experimental Psychology. $1962,63,217-226$.

HARTMAN, T. F \& ROSS, L. E. An alternative criterion for the elimination of "voluntary" responses in eyelid conditioning. Journal of Experimental Psychology, 1961, 61, 334-338.

HICKOK, C. W., GRANT, D. A., \& NORTH, J. A. Differential eyelid conditioning of voluntary form responses. Psychonomic Science, 1965, 3, 583-584.

LEVY, M. C. GRANT, D. A., \& CLARK, A. H. Reversal of conditioned discrimination of the eyelid response. Journal of Experimental Psychology, $1964,67,80-82$.

LOGAN, F. A. A comparison of avoidance and nonavoidance eyelid conditioning. Joumal of Experimental Psychology, $1951,42,390-393$

MOORE, J. W., \& GORMEZANO, I. Yoked comparisons of instrumental and classical eyelid conditioning. Journal of Experimental Psychology, 1961, 62 , $552-559$.

PERKINS, C. C., JR. An analysis of the concept of reinforcement. Psychological Review, 1968, 75, 155-172.

PROKASY, W. F., GRANT, D. A., \& MEYERS, N. A. Eyelid conditioning as a function of unconditioned stimulus intensity and intertrial interval. Journal of Experimental Psychology, 1958,55. 242-246.

SCHLOSBERG, H. The relationship between success and the laws of conditioning. Psychological Review, 1937, 44, 379-394.

SOLOMON, R, L, $\&$ BRUSH, E. $S$ Experimentally derived concepts of anxiety and aversion. In $M$. $R$. Jones (Ed.). Nebraska symposium on motivation. Lincoln: University of Nebraska Press, 1956.

SPENCE, $K$. W. \& ROSS, $L_{n}$ E. A methodological study of the form and latency of eyelid responses in conditioning. Journal of Experimental Psychology, 1959, 58, 376-381.

WINER, B. J. Statistical principles in experimental design. New York McGraw-Hill, 1962. 